\title{
Biomechanical comparison of different combinations of hook and screw in one spine motion unit - an experiment in porcine model
}

\author{
Ching-Lung Tai ${ }^{1}$, Li-Huei Chen${ }^{2}$ De-Mei Lee ${ }^{1}$, Mu-Yi Liu ${ }^{1}$ and Po-Liang Lai ${ }^{*}$
}

\begin{abstract}
Background: The biomechanical performance of the hooks and screws in spinal posterior instrumentation is not well-characterized. Screw-bone interface failure at the uppermost and lowermost vertebrae is not uncommon. Some have advocated for the use of supplement hooks to prevent screw loosening. However, studies describing methods for combined hook and screw systems that fully address the benefits of these systems are lacking. Thus, the choice of which implant to use in a given case is often based solely on a surgeon's experience instead of on the biomechanical features and advantages of each device.
\end{abstract}

Methods: We conducted a biomechanical comparison of devices instrumented with different combinations of hooks and screws. Thirty-six fresh low thoracic porcine spines were assigned to three groups (12 per group) according to the configuration used for of fixation: (1) pedicle screw; (2) lamina hook and (3) combination of pedicle screw and lamina hook. Axial pullout tests backward on transverse plane in the direction normal to the rods were performed using a material testing machine and a specially designed grip with self-aligned function.

Results: The pullout force for the pedicle screws group was significantly greater than for the hooks and the combination $(p<0.05)$. However, no significant difference was found between the hooks and the combination $(p>0.05)$.

Conclusions: Pedicle screws achieve the maximal pullout strength for spinal posterior instrumentation.

Keywords: Pedicle screw, Lamina hook, Biomechanical study, Porcine model

\section{Background}

The implantation of bone screws into the pedicle was reported in the early 1960s [1]. Pedicle screw fixation is regarded as a significant improvement over conventional methods for stabilizing the spine, which use wires, hooks or both. Pedicle screws provide three-column fixation, allowing shorter segment of instrumentation to be used to restore sagittal alignment. Despite these advantages, pedicle screws have drawbacks. For example, pedicle screws can bend or break particularly in the caudal segments $[2,3]$. There have been no clear biomechanical comparisons between hooks and screws. Although pedicle

\footnotetext{
*Correspondence: polianglai@gmail.com

2Department of Orthopaedic Surgery, Chang Gung Memorial Hospital, Chang Gung University College of Medicine, Taoyuan, Taiwan

Full list of author information is available at the end of the article
}

screw anchors offer three-dimensional correction, which is beneficial compared with hooks, pullout tests have shown that the purchase power of a single pedicle screw is greater than a single hook in healthy bone, but less powerful than a single hook in osteoporotic bone [4]. In osteoporotic vertebrae, the bone quality of the lamina is better than the bone quality in the vertebral body. To provide better curve correction and maintain a balanced spine, the anchoring of the implant to the bone should be very strong and resistant to loading.

Harrington's rod for the treatment of scoliosis was implemented in 1962 as the first implant for thoracic spine surgery [5,6]. This device is a non-segmental hook and rod system. The first attempt to provide segmental fixation was Luque's sublaminar wire [7,8]. Sublaminar wires provide stable fixation for each vertebral segment 
but do not reduce coronal spinal deformities. The development of the multiple segmental hook and rod system by Cotrel and Dubousset was a milestone in scoliosis surgery $[9,10]$. There are two types of hooks that used in this instrumentation: pedicle and lamina. Pedicle hooks provide stronger anchoring power and do not enter the neural foramen. However, they can only translate the correction force upward (cranially) in the thoracic spine. Lamina hooks can provide upward and downward (caudal) forces in the thoracic and lumbar spine. However, they must enter the neural canal to anchor to the lamina. Suk began using thoracic pedicle screws for scoliosis correction in 1991 and has since reported the highest curve correctivity of any system [11]. In spite of this encouraging result, the use of thoracic screws for scoliosis has not been widely accepted. Screw-bone interface failure at the uppermost and lowermost vertebrae is not uncommon. Some have advocated for the use of supplement hooks to prevent screw loosening [11-13]. However, the benefits of combined hook and screw methods are not clear. Thus, the choice of which implant to use in a given case is often been based solely on a surgeon's experience rater than on the biomechanical features and advantages of each device. The aim of this study was to measure the pullout strength of pedicle screws versus lamina hooks and combinations of screws and lamina hooks in porcine thoracic spine to simulate the surgical correction techniques used to treat scoliosis.

\section{Methods}

This study was approved by the committee of National Science Council of Taiwan. All experiments conformed to the regulations for the care and use of animals. The usage of the porcine spines was in accordance with the guidelines of replacement, reduction and refinement. Thirty-six fresh lower thoracic porcine spines were assigned to three groups (12 per group) according to their fixation configuration: (1) pedicle screws, (2) lamina hooks and (3) combination of screws and lamina hooks. In the screw group (1), pedicle screws were inserted into the neighboring vertebral bodies of one spine motion unit. In the hook group (2), a claw configuration composed of two hooks directed toward each other was used. In the combination group (3), the hooks were placed at the proximal vertebrae, while the screws were inserted into the distal vertebrae. The constructs were connected by rods. Figure 1 shows the pedicle screws, lamina hooks and rods (Mossmiami, Depuy, USA) used in the current study. Figure 2 shows the three different combinations of screws and hooks used for spinal instrumentation.

Implantation of the fixation screws was carried out under direct visualization. Radiological examinations were performed at the same time to confirm the depths and positions of the implanted screws in all of the specimens. An angled jig device was used to ensure accurate placement of the fixation screws. Axial pullout tests in a backward direction normal to that of the rods were performed using a material testing system (Bionix 858, MTS Corp., MN, USA). Custom-designed grips were secured to the actuator on the MTS machine. The grips consisted of universal ball-and-socket joints connected to steel plates. The plates had four variable attachment holes to accommodate specimens of different dimensions, along with four shoulder ball-and-socket joints lead to the four adjustable steel turnbuckles. The turnbuckles had rotating eyebolts on each end, which attached directly to the four exposed ends of the spinal rods extending from each of the constructs. The anterior portions of both segments of

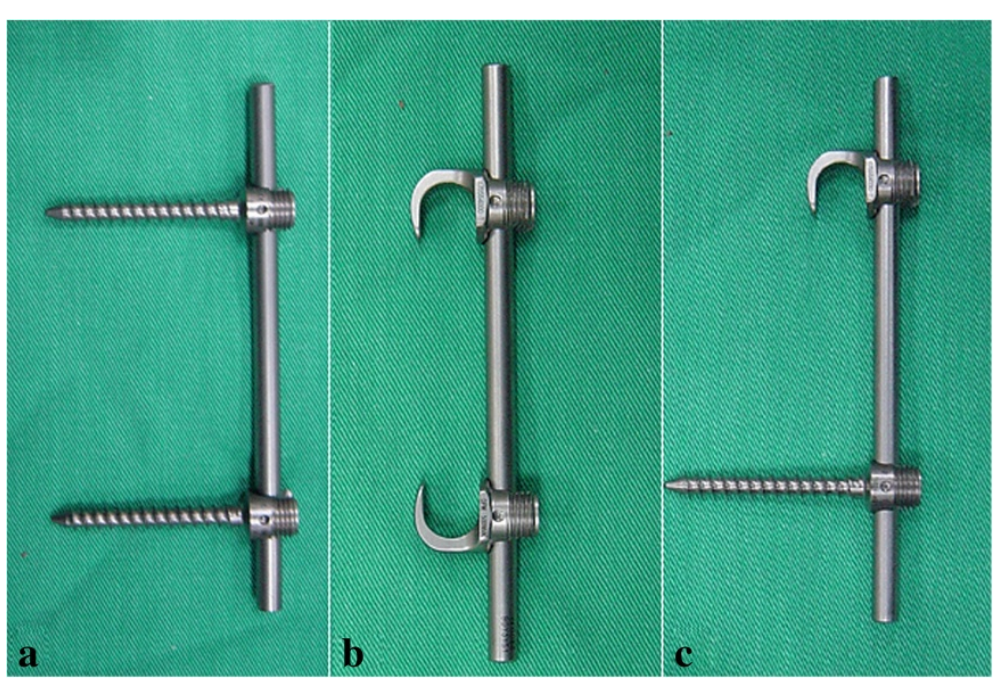

Figure 1 Photographs of (a) the pedicle screws, (b) the lamina hooks and (c) the combination of hooks and screws. 

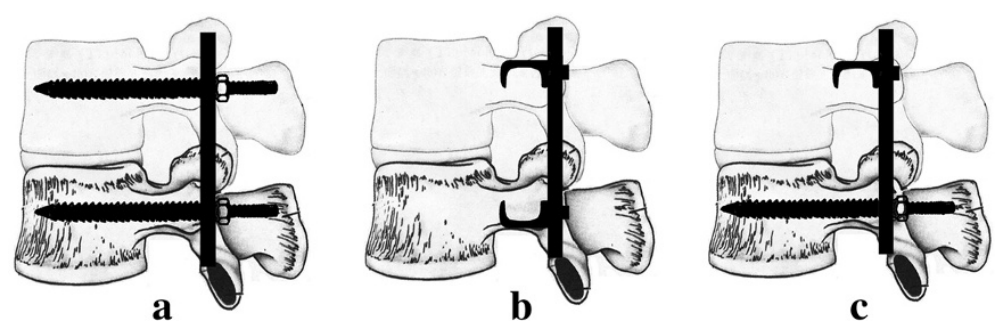

Figure 2 Schematics showing the three combinations of screws and hooks instrumented in one spine motion unit. (a) Pedicle screw,

(b) Lamina hook, and (c) Screw-lamina hook.

the spinal constructs were horizontally embedded in lowmelting point $\mathrm{Zn}$ alloy (Figure 3). After the specimens were positioned, external forces were applied at a constant loading rate of $20 \mathrm{~N}$ per second. The relationship between the force and displacement was recorded at an increment of $50 \mathrm{~N}$ by the MTS Teststar-II software. To evaluate the effects of the various combinations of screws and hooks on the stability of the spinal constructs, the magnitude of the force at failure for each individual specimen was selected for comparison.

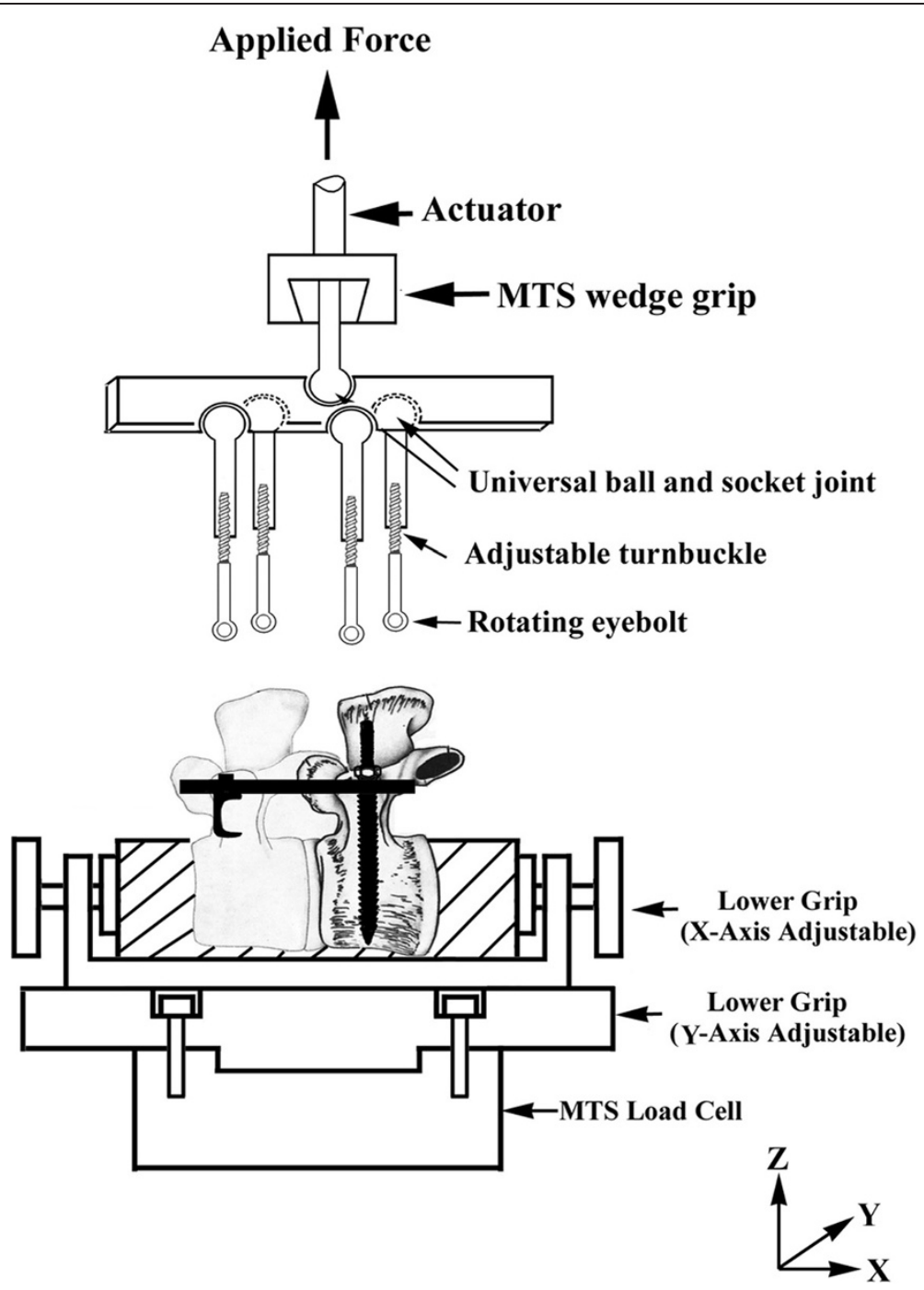

Figure 3 Schematic showing the experimental setup of pullout test. The force was applied in the direction normal to the rods. 


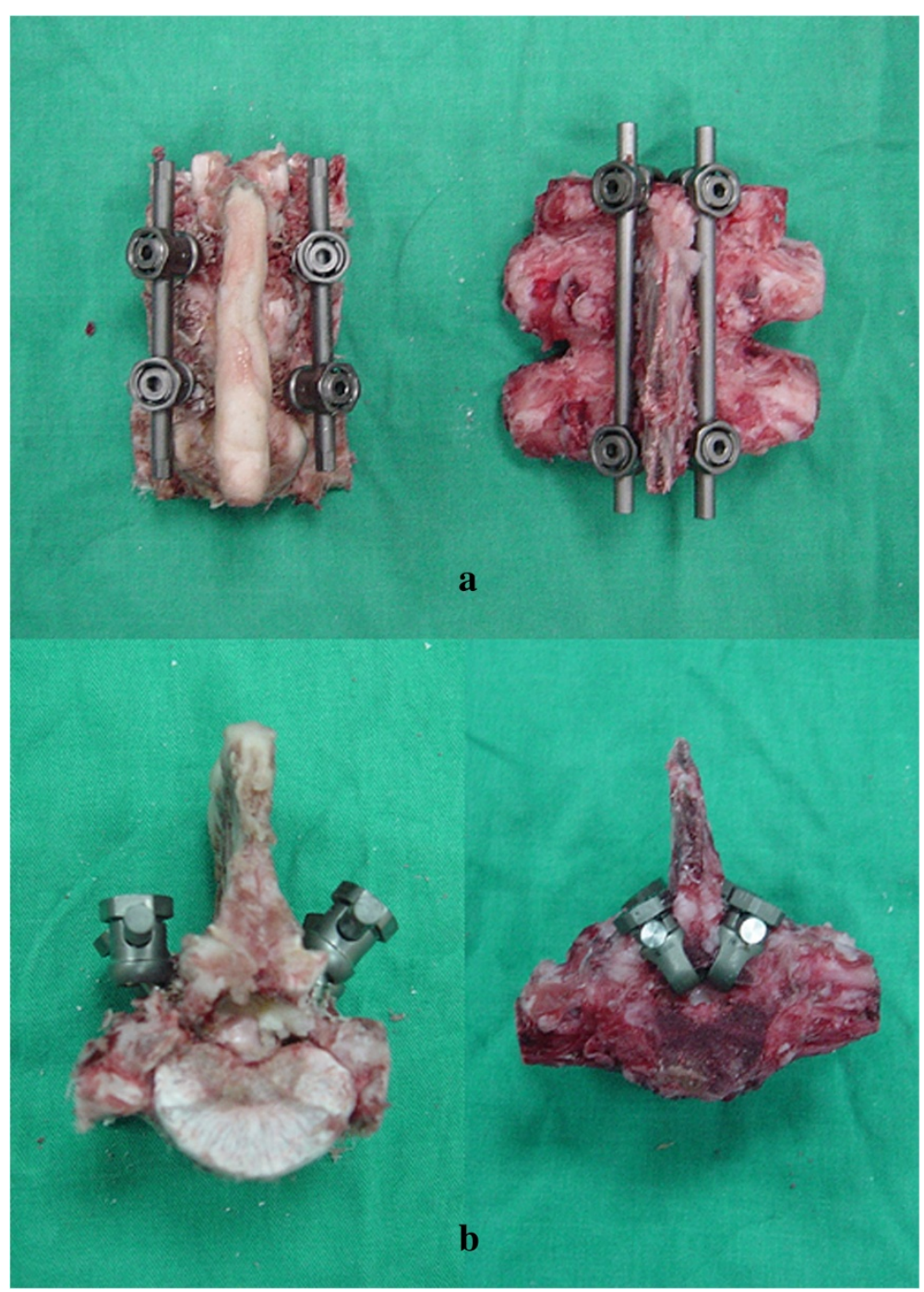

Figure 4 Spinal constructs instrumented with pedicle screws (left) and a combination of screws and hooks (right). (a) Posterior view, (b) Superior view.

\section{Results}

The spinal constructs instrumented with the screws and with the combinations of screws and hooks are shown in Figure 4. The corresponding specimens after the pullout test are shown in Figure 5. All of the specimens were examined after testing. The destruction of vertebra in the combination group was considerably more severe than in the screw group (Figure 5). In the screw group, the screws were pulled out without destruction of the spine. In the hook and combination groups, however, the spinal construct failed due to fracture of the lamina. There was no screw or hook breakage throughout the testing. The fixation of specimen on the embedding alloy site was well maintained from the pretest condition (Figure 5).

The maximum mean value of pullout force for the screw, hook and combination groups were 1,329 $\pm 381 \mathrm{~N}$,
$943 \pm 259 \mathrm{~N}$ and $1,065 \pm 297 \mathrm{~N}$, respectively (Figure 6). The maximum pullout force of the pedicle screw group was 1.41 times higher than the hook group; whereas the pedicle screw group was 1.25 times higher than the combination group. These results indicated that the pullout force for the pedicle screw group was significantly greater than the other groups $(\mathrm{p}<0.05)$. However, no significant differences were observed between the hook and combination groups $(\mathrm{p}>0.05)$.

\section{Discussion}

Because of the relatively early application of hooks for treating scoliosis, most surgeons are familiar with this technique. There are standard size hooks available for adolescent patients and miniature hooks available for small children (body weight $<30 \mathrm{~kg}$ ). However, there are 

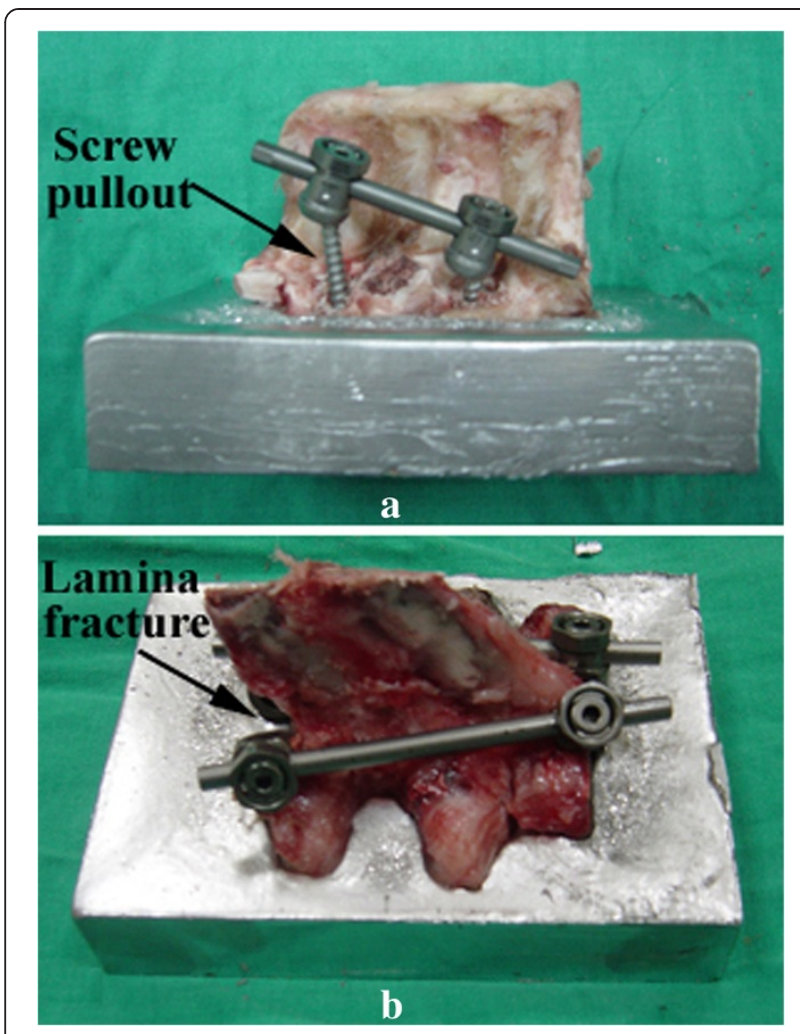

Figure 5 The spinal constructs after the pullout tests. (a) Spinal construct with pedicle screw instrumentations. The screws were pulled out without failure of the spinal construct. (b) Spinal construct with a combination of pedicle screws and lamina hooks. The spinal construct failed due to lamina fracture.

potential disadvantages associated with hook systems [12-14]. First, the tip of the lamina hook has to enter the neural canal, increasing the potential for injury to the spinal cord. Second, hooks engage only the posterior elements instead of engaging both the anterior and medial columns. Pedicle screws are more commonly used in the lumbar spine than in the thoracic spine. Placement of thoracic pedicle screws is an exact and demanding technique $[15,16]$. Surrounding the thoracic spine, there are many vital structures, including the trachea, aorta, segmental vessels, anterior vena cava, lung and spinal cord. Dr. Suk reported the use of thoracic pedicle screws to treat thoracic scoliosis in 1991 [11]. That report demonstrated improved radiographic results in patients treated with screw versus hook.

Spinal biomechanics have been studied in several ways. Using a long segment construct to study the biomechanics of implants is time consuming and impractical. To conquer this problem, it is reasonable to use a motion unit to study spinal biomechanics. The previous literature has examined the pullout behavior of pedicles, which were loaded by tension during flexion $[17,18]$. This situation can be exacerbated in long instrumentation constructs, where large axial pullout forces are generated due to cantilever bending at the proximal levels during forward flexion $[17,18]$. Our results indicated that the pullout force for pedicle screws was significantly greater than for hook and combinations of screws and hooks $(\mathrm{p}<0.05)$. No significant difference was observed between the hook and combination groups $(p>0.05)$. Several studies have described the mechanical roles of pedicle screws and lamina hooks in spinal posterior instrumentation [19-21]. However, the anchoring strength for combinations of screws and hooks was not considered. Liljenqvist et al. [19] investigated the axial pullout strength of pedicle screws versus laminar hooks in the thoracic spine with respect to the surgical correction techniques used to treat scoliosis. Their results indicated that the average pullout strength of pedicle screws was significant higher than for laminar hooks. These observations were consistent with our results. Murakami et al. [20] compared fixation in the thoracolumbar spine using pedicle screws combined with infra-lamina hooks (at both the cranial and caudal ends of the same vertebrae) with fixation using pedicle screws alone. They concluded that a pedicle screw combined with

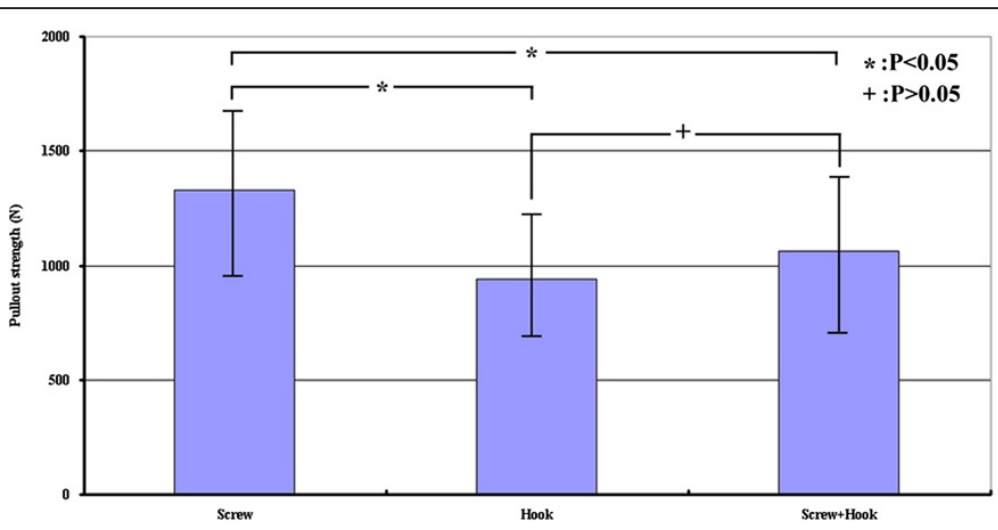

Figure 6 Pullout force for the screw, hook and combination groups. The pullout force for the screw group was significantly greater than for the hook and combination groups $(p<0.05)$. However, no significant difference was found between the hook and combination groups $(p>0.05)$. 
an infra-lamina hook offers significantly greater strength compared to a pedicle screw alone. In osteoporotic vertebrae, the bone quality of the lamina is better than the bone quality in the vertebral body. Therefore, the bone mineral density might be an important consideration in the selection of screws or hooks. Hackenberg et. al [21] studied the fixation strength of pedicle screws versus pedicle and laminar hooks in the thoracic spine in relation to the bone mineral density. They concluded that pedicle screws may be beneficial for thoracic spine instrumentation because they offer significantly more resistant to axial and tangential loads than pedicle and lamina hooks on the condition that bone mineral density is higher than $100 \mathrm{mg}$ hydroxyapatite/mL. However, the difference is not significant if bone mineral density is lower than $100 \mathrm{mg}$ hydroxyapatite $/ \mathrm{mL}$.

Our study is an in vitro analysis of specimens prepared in a laboratory environment, which does not necessarily represent clinical circumstances. There are several limitations to our study. First, we used porcine spines instead of human cadaveric spines. Although the physiological structures are somewhat different from those of human cadaveric spines, animal spines are the most convenient choice for performing the experiments when human cadaveric spines cannot be accessed. Numerous studies $[22,23]$ have been performed to evaluate the biomechanical behavior of spinal columns. These studies typically use porcine spines as models for the human spine. Smit's report [23] showed similarities in the mechanics of quadruped and human spines. He concluded that a quadruped can serve as a valuable model for studying the human spine in spite of its horizontal position. Second, our work is limited to static loading (pullout) and does not consider other physiological loads. In actual physiological situations, the screw/bone and hook/bone interfaces are subjected to complex dynamic multi-directional loads. Consequently, the choice between a pedicle screw and a hook should not be determined solely based on the pullout strength. In practice, fixation devices with the ability to correct deformity, restore sagittal balance, prevent deterioration and influence adjacent segments should all be considered. Although the loading mode for pullout does not necessarily represent the actual physiological loading condition and may have great impact on the clinical relevance, the specimens used in this study were all prepared and tested in a uniform and reproducible manner. Thus, we believe that these results will provide useful information for orthopedic surgeons to assess spinal posterior instrumentation systems.

\section{Conclusions}

The pedicle screw instrumentation achieves the maximal pullout strength for spinal posterior instrumentation. Based on this comparative study, surgeons should be better informed for selecting the optimal fixation method for the thoraco-lumbar spine before surgery.

\section{Competing interests}

The authors declare that they have no competing interests.

\section{Authors' contributions}

CLT participated in the study design, data collection, statistical analyses and drafting of the manuscript. LHC, DML and MYL participated in the study design. PLL advised and assisted with drafting the manuscript. All of the authors read and approved of the final manuscript.

\section{Acknowledgements}

The authors would like to thank National Science Council of Taiwan and Chang Gung Memorial Hospital for financial support (CMRPD280021, CMRPD280022).

\section{Author details}

${ }^{1}$ Graduate Institute of Medical Mechatronics, Department of Mechanical Engineering, Chang Gung University, Taoyuan, Taiwan. ${ }^{2}$ Department of Orthopaedic Surgery, Chang Gung Memorial Hospital, Chang Gung University College of Medicine, Taoyuan, Taiwan.

Received: 29 October 2013 Accepted: 30 May 2014

Published: 9 June 2014

\section{References}

1. Roy-Camille R, Saillant G, Mazel C: Internal fixation of the lumbar spine with pedicle screw plating. Clin Orthop Relat Res 1986, 203:7-17.

2. Hicks JM, Singla A, Shen FH, Arlet V: Complications of pedicle screw fixation in scoliosis surgery: a systematic review. Spine 2010, 35(11):E465-70.

3. McLain RF, Sparling E, Benson DR: Early failure of short-segment pedicle instrumentation for thoracolumbar fractures. A preliminary report. $J$ Bone Joint Surg Am 1993, 75(2):162-7.

4. Hasegawa K, Takahashi HE, Uchiyama S, Hirano T, Hara T, Washio T, Sugiura $T$, Youkaichiya $M$, lkeda $M$ : An experimental study of a combination method using a pedicle screw and laminar hook for the osteoporotic spine. Spine 1997, 22(9):958-62.

5. Harrington PR: Correction and internal fixation by spine instrumentation. J Bone Joint Surg Am 1962, 44:591-610.

6. Hitchon PW: Harrington distraction rods for thoracic and lumbar fractures. In Techniques in Spinal Fusion and Stabilization. Edited by Hitchon PW, Traynelis VC, Rengachary SS. New York: Thieme; 1995:204-208.

7. Luque ER: Segmental spine instrumentation: A method of rigid internal fixation of the spine to induce arthrodesis. Orthop Trans 1980, 4:391.

8. Hitchon PW, Follett KA: Luque instrumentation for the thoracic and lumbar spine. In Techniques in Spinal Fusion and Stabilization. Edited by Hitchon PW, Traynelis VC, Rengachary SS. New York: Thieme; 1995:198-203.

9. Cotrel Y: What new Cotrel-Dubousset instrumentation is used in the treatment of idiopathic scoliosis. Acta Orthop Belg 1992, 58(Suppl 1):111-4.

10. Bennett GJ: Cotrel-Dubousset instrumentation for thoracolumbar instability. In Techniques in Spinal Fusion and Stabilization. Edited by Hitchon PW, Traynelis VC, Rengachary SS. New York: Thieme; 1995:209-217.

11. Suk SI, Lee CK, Kim WJ, Chung YJ, Park YB: Segmental pedicle screw fixation in the treatment of thoracic idiopathic scoliosis. Spine 1995, 20(12):1399-1405.

12. Benzel EC, Baldwin NG, Ball PA: Texas Scottish Rite Hospital Hook-Rod spinal fixation. In Techniques in Spinal Fusion and Stabilization. Edited by Hitchon PW, Traynelis VC, Rengachary SS. New York: Thieme; 1995:229-239.

13. Margulies JY, Casar RS, Caruso SA: The mechanical role of laminar hook protection of pedicle screws at the caudal end vertebra. Eur Spine J 1997, 6(4):245-248.

14. Grisafi FN, Emery SE: Migration of laminar hook causing thoracic myelopathy eight years post scoliosis surgery: a case report. Spine 2010, 35(6):E228-30

15. Ebelke DK, Asher MA, Neff JR, Kraker DP: Survivorship analysis of VSP spine instrumentation in the treatment of thoracolumbar and lumbar burst fractures. Spine 1991, 16(8 Suppl):S428-32. 
16. Zindrick MR, Wiltse LL, Widell EH, Thomas JC, Holland WR, Field BT, Spencer CW: A biomechanical study of interpeduncular screw fixation in the lumbosacral spine. Clin Orthop 1986, 203:99-112.

17. Ashman RB, Galpin RD, Corin JD, Johnston CE: Biomechanical analysis of pedicle screw instrumentation systems in a corpectomy model. Spine 1989, 14(12):1398-405

18. Law M, Tencer AF, Anderson PA: Caudo-cephalad loading of pedicle screws: mechanisms of loosening and methods of augmentation. Spine 1993, 18(16):2438-43.

19. Liljenqvist U, Hackenberg L, Link T, Halm H: Pullout strength of pedicle screws versus pedicle and laminar hooks in the thoracic spine. Acta Orthop Belg 2001, 67(2):157-63.

20. Murakami H, Tsai KJ, Attallah-Wasif ES, Yamazaki K, Shimamura T, Hutton WC: A biomechanical assessment of infra-laminar hooks as an alternative to supra-laminar hooks in thoracolumbar fixation. Spine 2006, 31(9):967-71.

21. Hackenberg $L$, Link T, Liljenqvist U: Axial and tangential fixation strength of pedicle screws versus hooks in the thoracic spine in relation to bone mineral density. Spine 2002, 27(9):937-42.

22. Kaigle A, Ekstrom L, Holm S, Rostedt M, Hansson T: In vivo dynamic stiffness of the porcine lumbar spine exposed to cyclic loading: influence of load and degeneration. J Spinal Disord 1998, 11(1):65-70

23. Smit TH: The use of a quadruped as an in vivo model for the study of the spine - biomechanical considerations. Eur Spine J 2002, 11(2):137-144.

doi:10.1186/1471-2474-15-197

Cite this article as: Tai et al:: Biomechanical comparison of different combinations of hook and screw in one spine motion unit - an experiment in porcine model. BMC Musculoskeletal Disorders 2014 15:197.

\section{Submit your next manuscript to BioMed Central and take full advantage of:}

- Convenient online submission

- Thorough peer review

- No space constraints or color figure charges

- Immediate publication on acceptance

- Inclusion in PubMed, CAS, Scopus and Google Scholar

- Research which is freely available for redistribution 